\title{
Combined Pre-Treatment and Causticization of Cotton Fabric for Improved Dye Uptake
}

Molla TA ${ }^{1 *}$, Chavan $\mathbf{R B}^{1}$ and Nierstrasz $\mathbf{V}^{2}$

${ }^{1}$ Ethiopian Institute of Textile and Fashion Technology,

Bahir Dar University, Ethiopia

${ }^{2}$ Textile Materials Technology, Department of Textile

Technology, The Swedish School of Textiles, University of

Boras, Sweden

*Corresponding author: Molla Tadesse Abate, Ethiopian Institute of Textile and Fashion Technology, Bahir Dar University, Ethiopia

Received: April 15, 2017; Accepted: J une 22, 2017;

Published: J une 29, 2017

\begin{abstract}
Conventionally, cotton fabric is subjected to a series of separate pretreatment processes such as desizing, scouring, and bleaching to remove natural and added impurities for satisfactory dyeing and finishing. When the sole purpose is to improve the dye uptake, cotton fabric is subjected to yet another separate process called causticization, a treatment of cotton fabric at reduced concentration of caustic soda (110-150 g/L) compared to mercerization. All these processes i.e. desizing, scouring, and bleaching are lengthy and require large amount of water, energy, chemicals, and time which lead to increase in cost and productivity loss.
\end{abstract}

In this paper, a combined desizing, scouring, bleaching and causticization process with shorter processing time is reported. Single factor randomized experimental design was used for process optimization. Based on experiments, the optimum recipe consisted of padding the gray cotton fabric using a twodip, two-nip technique in a bath containing $\mathrm{NaOH} 140 \mathrm{~g} / \mathrm{L}$; Sodium Per Borate (SPB) $40-45 \mathrm{~g} / \mathrm{L}$; wetting agent $1 \mathrm{~g} / \mathrm{L}$, batching for $30 \mathrm{~min}$ at room temperature and washing the treated fabric with $1 \mathrm{~g} / \mathrm{L}$ emulsifier twice for 15 minutes each at boil with $3 \%$ owf SPB added during the second wash, rinsed with hot and cold water and air dried.

The results showed excellent wettability, good degree of whiteness, minimum loss of tensile strength and higher dye uptake compared to uncausticized commercially bleached cotton fabric.

Keywords: Causticization; Sodium perborate; Dye uptake; Cold-pad-batch; Whiteness index

\section{Introduction}

Gray cotton fabric obtained after weaving contains natural impurities like oil, fat, wax, pectin, and coloring matter within the fiber structure, and added impurities of sizing chemicals (e.g. starch, polyvinyl alcohol, lubricants) usually applied on warp yarns to avoid breakages during the weaving process as well as machine oil and grease due to contamination $[1,2]$. Presence of these impurities hinders wetting and whiteness of the fabric. Therefore, efficient removal of these impurities is required during cotton fabric preparation to guarantee effective dyeing, printing and finishing processes.

Typical grey cotton fabric preparation treatment includes desizing, scouring, and bleaching. It may also include mercerizing which is an optional process to improve luster, strength, moisture absorption, and dye uptake of cotton fabric. There is yet another separate pre-treatment process called causticization (also known as semi-mercerization): a pre-treatment of cotton fabric with less concentration $(110-150 \mathrm{~g} / \mathrm{L})$ of caustic soda at room temperature under slack conditions. It is also an optional process specifically carried out to improve the dye uptake [3,4]. These sequences of operations i.e. desizing, scouring, bleaching and causticization are carried out separately and are time consuming requiring large amounts of water and energy as well as a variety of chemicals affecting the cost and productivity.
Several attempts have been made to carry out all three preparatory processes simultaneously. A combined pretreatment of cotton was suggested by Parikh as early as 1971 by using a chelating agent Diethylene Triamine Pentaacetic Acid (DTPA) as stabilizer for hydrogen peroxide [5]. Sahakari developed a process known as Scourex for combined desizing, scouring and bleaching of cotton using an aqueous emulsion a solvent, non-ionic surfactant, sodium hydroxide and hydrogen peroxide [6]. Gulrajani and Sukumar suggested a solvent assisted aqueous preparatory process in which sodium hydroxide (scouring agent) has been replaced by solventnon-ionic surfactant-pine oil combination along with hydrogen peroxide [7]. Prabhaharan and Venkat Rao made an attempt to simultaneously desize, scour and bleach wet grey cotton fabric having $25 \%$ moisture, $\mathrm{pH} 5$ (adjusted with acetic acid) in a specially designed ozone chamber for 1-7 minutes, followed by hot water wash. It was observed that the ozone treatment for 1-2 minutes was adequate to get acceptable removal of starch, wax and coloring matter making the fabric ready for dyeing. However, for high degree of whiteness it was essential to subject to ozonated fabric to a separate $\mathrm{H}_{2} \mathrm{O}_{2}$ bleaching operation [8]. Tzanko et al. suggested closed-loop enzymatic desizingscouring-bleaching process using combination of amylase, pectinase and glucose oxidase enzymes in a single bath. It was postulated that amylase enzyme hydrolyzed the sizing agent into glucose. Glucose oxidases catalyzed the oxidation of $\mathrm{B}$-D-glucose to D-glucono$\omega$-lactone and simultaneously generated hydrogen peroxide for 
bleaching. The pectinase enzyme facilitated the removal of noncellulosic impurities from cotton [9]. Spicka modified this process by converting the generated hydrogen peroxide into peracetic acid by incorporating the bleach activator Tetra Acetyl Ethylene Diamine (TAED). Bleaching took place at $50^{\circ} \mathrm{C}$ and neutral $\mathrm{pH}$, where peracetic acid is most effective [10]. Teli and Tesfaye suggested a combined enzymatic desizing and scouring process for cotton textile by using a mixture of commercial BEISOL T2090 and BEISOL PRO enzymes. To optimize the combined bio-desizing and bioscouring, the BoxBehnken Design (BBD) was utilized during the investigation. It was observed that under optimum conditions the treated fabric showed acceptable water absorbency and whiteness [11]. Rachana et al. investigated a process for combined pre-treatment cotton and dyeing with direct dyes. Desizing, scouring, and bleaching and dyeing of cotton was carried out in a single bath without intermediate washing, thus without replacing the liquor bath until the end of dyeing. The treatment bath consisted of a standardized recipe of $1 \mathrm{~g} / \mathrm{L}$ wetting agent, $5 \mathrm{~g} / \mathrm{L} \mathrm{NaOH}, 3 \mathrm{~mL} / \mathrm{L} \mathrm{H}_{2} \mathrm{O}_{2}(50 \% \mathrm{w} / \mathrm{v}), 1 \mathrm{~g} / \mathrm{L}$ sodium silicate, the required amount of direct dyes and $15 \mathrm{~g} / \mathrm{L}$ Glauber's salt. The depths of shade and fastness properties of dyed fabric were comparable to traditional dyeing process after bleaching. It was claimed that the combined process saved $83.1 \%$ water, $88.6 \%$ energy (thermal) and $79.3 \%$ time than the conventional processes [12]. Huang and Jan explored the effect of Tetra Acetyl Ethylene Diamine (TAED) and sodium perborate $\left(\mathrm{NaBO}_{3}\right)$ on Cotton/Nylon $(\mathrm{C} / \mathrm{N})$ fabrics treated by one-bath/two-steps method. By using a pretreatment solution composed, each of $0.2 \mathrm{~g} / \mathrm{L} \mathrm{NaOH}, 2 \mathrm{~g} / \mathrm{L} \mathrm{H}_{2} \mathrm{O}_{2}$ (first step) and $2 \mathrm{~g} / \mathrm{L}$ of TAED and $\mathrm{NaBO}_{3}$ (second step) at $70^{\circ} \mathrm{C}$ for $30 \mathrm{~min}$, fabric treated by this method showed absorbency and whiteness properties superior to those treated by traditional methods, with the exception of strength [13]. A closed-loop process for cotton fabric preparation (desizing, scouring, bleaching) using Sodium Perborate (SPB) was investigated by Zahran. The process was carried out under different conditions of $\mathrm{pH}, \mathrm{SPB}$ concentration, temperature and duration of treatment. The effectiveness of SPB as an eco-friendly bleaching agent was assessed by monitoring the treated sample for whiteness index, fabric weight loss, tensile strength and carboxyl content. The process was found to be both ecological, economical and energy conserving. Tentative mechanism of sodium perborate as a bleaching agent was suggested [14]. Tamene and Chavan reported a process of causticization of grey cotton by padding or treatment on jigger with $140 \mathrm{~g} / \mathrm{L}$ caustic soda followed by two stage combined desizing, scouring and bleaching (first stage) and dyeing on jigger without drying (second stage). The results showed complete removal of starch, instant water drop absorption and good whiteness. The causticization of grey cotton fabric showed improvement in dye uptake of selected direct, reactive and vat dyes to an extent of $24-55 \%$ as compared to uncausticized cotton fabric [15].

From the above literature search, there is no study reported which combines desizing, scouring, bleaching and causticization of cotton in a single operation.

In the present study with the aim to improve dye uptake and to save time, energy and chemical usage, a single step process for desizing, scouring, bleaching and causticization of cotton fabric is developed by using sodium perborate as the eco-friendly bleaching agent.

\section{Experimental}

\section{Materials}

Starch-sized, plain weave grey cotton fabric (140 GSM, 60 EPI and 46 PPI) supplied by Bahir Dar Textile Share Company, Ethiopia was used. Laboratory grade sodium perborate tetrahydrate $\left(\mathrm{NaBO}_{3} \cdot 4 \mathrm{H}_{2} \mathrm{O}\right)$, caustic soda, hydrogen peroxide (35\% strength), sodium chloride, non-ionic wetting agent, and commercial emulsifier (Tubigat A60), sodium silicate, organic stabilizer, sodium hydrosulphite, sodium carbonate purchased from Afro Germen Company were used. Direct dye (Tubantin Blue FF2GL 200), bi-functional reactive dye (Bezaktiv blue S-max) and vat dye (vat green IN class) supplied by Bezema, Switzerland were used.

\section{Methods}

Two sets of experiments were carried out: a screening experiment to determine the main factor(s) and best procedure; second, optimization of the combined treatment;

\section{Screening experiments}

Screening experiments were conducted to determine the significance of each factor on the outcome, and to select the main factor(s) and procedure(s) for further optimization. Experiments were carried out by varying parameters such as sodium perborate concentration, batching time and washing conditions. Their influence was evaluated by measuring percentage loss in fabric weight, iodine test for extent of starch removal, water absorbency and Whiteness Index (WI). In these experiments, the grey fabric samples were padded using two-dip, two-nip technique with caustic soda $140 \mathrm{~g} / \mathrm{L}$, Sodium Per Borate (SPB) $10-70 \mathrm{~g} / \mathrm{L}$ and wetting agent $1 \mathrm{~g} / \mathrm{L}$ with a wet pick up of $100 \%$. Then, the padded fabric samples were batched (30min-24hour) at room temperature, and washed (1-3 times) with $1 \mathrm{~g} / \mathrm{L}$ solution of emulsifier at boil for 15 minutes each, and final cold water rinsing. A Material to Liquor Ratio (MLR) of 1:25 was used for all the samples.

\section{Combined treatment optimization}

The grey cotton fabric samples were treated with $140 \mathrm{~g} / \mathrm{L}$ caustic soda, with variable concentrations of sodium perborate $(10-70 \mathrm{~g} / \mathrm{L})$ at $5 \mathrm{~g} / \mathrm{L}$ intervals containing $1 \mathrm{~g} / \mathrm{L}$ wetting agent. The caustic soda used was diluted three hours prior to the beginning of the experiment to bring the solution to room temperature since dilution of caustic soda is an exothermic process. A two-dip, two-nip padding technique was used, and then the samples were rolled on glass rods, covered with a plastic sheet, and batched $30 \mathrm{~min}$ at ambient temperature $\left(20-250^{\circ} \mathrm{C}\right)$. Then, the batched samples were washed twice for $15 \mathrm{~min}$ each time with $1 \mathrm{~g} / \mathrm{L}$ emulsifier at boil, keeping the MLR at 1:25. During the second wash, $3 \%$ (owf) of sodium perborate was added, and finally the samples were rinsed in hot and cold water and air-dried.

\section{Experimental design for optimization}

The experimental setup was based on a single factor completely randomized design. Design expert software (version 8.0.7.1) was used for randomization and data analysis. Experiments were carried out by varying the concentration of sodium perborate at $5 \mathrm{~g} / \mathrm{L}$ intervals. The concentration of sodium perborate was the main factor considered for optimization since the other factors had less effect on the whiteness index. All experiments were performed in duplicate, and the averages 
of results were taken as a response.

\section{Dyeing}

The commercially bleached and separately causticized and single stage desized, scoured, bleached and causticized samples were dyed using selected direct dye (Tubantin Blue FF2GL 200), reactive dye Bezaktiv blue S-max (bi-functional) and vat dye (vat green IN class) Dyes. The dyeing procedure was as per dye manufacturer recommendations for each dye class.

\section{Measurements}

Assessment of weight loss: The amount of impurities removed was determined by assessing the weight loss after the treatment. Weights of the samples were measured before and after treatment and are expressed as a percentage loss in fabric weight, according to equation (1)

Loss in fabric weight $(\%)=\left(\mathrm{W}_{1}-\mathrm{W}_{2}\right) / \mathrm{W}_{1} \times 100-\ldots$ where, $\mathrm{W}_{1}$ and $\mathrm{W}_{2}$ are the weight $(\mathrm{g})$ of untreated (original) and treated samples, respectively.

Determination of residual starch: The presence of residual starch was qualitatively assessed by dropping a diluted iodine solution on a wetted fabric area, and the color change was observed. Absence of deep blue color indicates the removal of starch.

Assessment of absorbency: A drop of water is allowed to fall from a fixed height onto the samples and the time required for the water drop to disappear is measured and recorded as a wetting time as per AATCC Test method 79-2007 [16].

Determination of Whiteness Index (WI): The CIE whiteness index was calculated for each sample as per AATCC test method 110-1995 [17]. It was measured using Gretag Macbeth color-eye 3100 spectrophotometer. Each sample was conditioned, folded twice to ensure opacity, and measurements were taken at three separate points and averaged.

Determination of strength loss: The warp yarn tensile strength of the cotton yarn before and after treatment was examined to assess the strength loss during pre-treatment. Six fabric samples, and from each sample 25 warp yarns were removed based on the standard sampling procedure and their tensile strength were tested using Splice Scanner 2, 25087 Salo (Italy) yarn strength testing equipment. Then the loss in strength was calculated according to equation (2).

$$
\text { Strength loss }(\%)=\left(\mathrm{N}_{1}-\mathrm{N}_{2}\right) / \mathrm{N}_{1} \times 100 \ldots
$$

where, $\mathrm{N}_{1}$ and $\mathrm{N}_{2}$ are the strength of untreated (original) and treated samples, respectively.

Determination of color yield: The dye uptake was determined by measuring the K/S values on color-eye 3100 spectrophotometer (Gretag Macbeth, USA) at the maximum wavelength of absorption for each sample. The test samples were hot-pressed to remove crease and conditioned, folded four times to ensure opacity before measurement. Triplicate measurements were performed for each sample, and the data were averaged.

\section{Results and Discussion}

\section{Screening the parameters}

The screening experiments were performed to assess the effect of
Table 1: Effect of SPB concentration on quality parameters (screening experiment), (Batching time $24 \mathrm{hrs}$ ).

\begin{tabular}{|c|c|c|c|c|}
\hline [SPB] g/L & WI & Weight loss\% & lodine test & Wettability \\
\hline 8 & 26 & 9.55 & Light violet colour & Instantaneous \\
\hline 10 & 30 & 9.34 & Light violet colour & Instantaneous \\
\hline 12 & 32 & 9.47 & Light violet colour & Instantaneous \\
\hline 14 & 34 & 9.59 & Light violet colour & Instantaneous \\
\hline 16 & 33 & 9.66 & Light violet colour & Instantaneous \\
\hline 20 & 45 & 9.75 & Light violet colour & Instantaneous \\
\hline 30 & 59 & 9.83 & Light violet colour & Instantaneous \\
\hline
\end{tabular}

Table 2: Effect batching time on quality parameter (screening experiment), (SPB concentration $30 \mathrm{~g} / \mathrm{L})$.

\begin{tabular}{|c|c|c|c|c|}
\hline Batch time & WI & Weight loss\% & lodine test & Wettability \\
\hline $30 \mathrm{~min}$ & 58 & 9.43 & Light violet colour & Instantaneous \\
\hline $1 \mathrm{hr}$ & 55 & 9.44 & Light violet colour & Instantaneous \\
\hline $2 \mathrm{hr}$ & 57 & 9.47 & Light violet colour & Instantaneous \\
\hline $12 \mathrm{hr}$ & 59 & 9.51 & Light violet colour & Instantaneous \\
\hline $24 \mathrm{hr}$ & 59 & 9.50 & Light violet colour & Instantaneous \\
\hline
\end{tabular}

Table 3: Effect of different recipes/procedures on quality parameter.

\begin{tabular}{|c|c|c|c|}
\hline & \multicolumn{3}{|c|}{ Recipe/Procedure } \\
\hline Parameters & Recipe 1 & Recipe 2 & Recipe 3 \\
\hline WI & 36 & 67 & 69 \\
\hline Weight loss (\%) & 9.54 & 9.34 & 9.44 \\
\hline Absorbency & Instantaneous & Instantaneous & Instantaneous \\
\hline Iodine test & Light violet & Light violet & Light violet \\
\hline
\end{tabular}

Table 4: Effect of SPB concentration on quality parameters.

\begin{tabular}{|l|l|l|l|l|}
\hline [SPB] g/L & Weight loss (\%) & Strength loss (\%) & lodine test & Absorbency \\
\hline
\end{tabular}

\begin{tabular}{|c|c|c|c|l|}
\hline 10 & 9.34 & 2.69 & Light violet & Instantaneous \\
\hline 20 & 9.55 & 4.30 & Light violet & Instantaneous \\
\hline 30 & 9.59 & 5.91 & Light violet & Instantaneous \\
\hline 40 & 9.6 & 7.53 & Light violet & Instantaneous \\
\hline 50 & 9.62 & 9.68 & Light violet & Instantaneous \\
\hline 60 & 9.64 & 10.22 & Light violet & Instantaneous \\
\hline 70 & 9.64 & 12.90 & Light violet & Instantaneous \\
\hline
\end{tabular}

Sodium Perborate (SPB) concentration, batching time and different procedures on the fabric quality. For this, Whiteness Index (WI), water drop absorbency, percentage loss in fabric weight, and iodine test were used to evaluate the efficiency. The results are shown in Table 1. It was observed that, at all the concentrations sodium perborate, the removal of starch and other impurities were effective as indicated by Weight loss, iodine test and wettability results. However, the degree of whiteness increased with the concentration of sodium perborate. This indicated the requirement of additional experiments to determine the optimum concentration of SPB for improved whiteness value.

Table 2 shows the effect of batching time on the WI. Samples were batched for 30min, 1hour, 2hour, 12 hour and 24 hour using $30 \mathrm{~g} / \mathrm{L}$ SPB concentration (other chemical concentrations remain the same as shown in the method section) to assess the effect of batching 


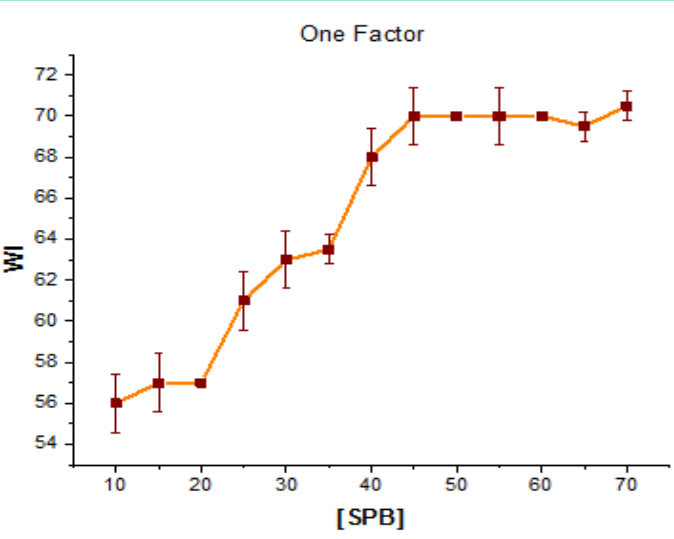

Figure 1: Effect of SPB concentration $\mathrm{g} / \mathrm{L}$ on the whiteness index.

time on the WI. Here also the removal of starch and other impurities was achieved at all batching times, and the WI was found to be independent of the duration of batching. This shows that the batching time is not the main parameter affecting the whiteness.

Finally, the following three recipes/procedures were tested to evaluate possible combination of chemicals for effective removal of natural and added impurities including coloring matter from the gray cotton fabric.

Procedure 1: $\mathrm{NaOH} 140 \mathrm{~g} / \mathrm{L}, \mathrm{H}_{2} \mathrm{O}_{2} 3 \%$ (owf), Sodium silicate $2 \%$ (owf), wetting agent $1 \mathrm{~g} / \mathrm{L} \rightarrow \mathrm{Pad} \rightarrow$ Batch $30 \mathrm{~min} . \rightarrow$ wash twice at boil with $1 \mathrm{~g} / \mathrm{L}$ emulsifier $\rightarrow$ hot and cold wash $\rightarrow$ dry.

Procedure 2: $\mathrm{NaOH} 140$ g/L, H2O2 3\% (owf), Sodium silicate $2 \%$ (owf), wetting agent $1 \mathrm{~g} / \mathrm{L} \rightarrow \mathrm{Pad} \rightarrow$ batch for $30 \mathrm{~min} \rightarrow$ wash twice at boil with $1 \mathrm{~g} / \mathrm{L}$ emulsifier and 3\% (owf) SPB was added during second wash $\rightarrow$ hot and cold wash $\rightarrow$ dry.

Procedure 3: $\mathrm{NaOH} 140 \mathrm{~g} / \mathrm{L}, \quad \mathrm{SPB} \quad 30 \mathrm{~g} / \mathrm{L}, \quad 1 \mathrm{~g} / \mathrm{L}$ wetting agent $\rightarrow$ Pad $\rightarrow$ batch for $30 \mathrm{~min} \rightarrow$ wash twice at boil with $1 \mathrm{~g} / \mathrm{L}$ emulsifier and 3\% (owf ) SPB was added during second wash $\rightarrow$ hot and cold wash $\rightarrow$ dry.

The results of these recipes/procedures are shown in the Table 3.

As can be seen from the result in Table 3, the average WI obtained using recipe 1 was minimal. This can be accounted to the rapid decomposition of hydrogen peroxide due to $\mathrm{pH}$ conditions created by causticizing concentration of $\mathrm{NaOH}(140 \mathrm{~g} / \mathrm{L})$. It is well known that the removal of natural coloring matters from cotton mainly depends on the stability of the oxidizing agent $\left(\mathrm{H}_{2} \mathrm{O}_{2}\right.$ in this case) [18]. In case of procedure 2 and 3 which contain SPB, the whiteness index improved significantly depicting the effectiveness SPB as a bleaching agent under strong alkaline condition. It was also noticed that adding a small amount of SPB during the second wash contributed to the improvement of the WI.

\section{Optimization}

To achieve optimum process conditions, the whiteness index, tensile strength and wetting time of commercial bleach cotton fabric was taken as a standard. Based on the screening experiments, the WI was the only factor which needed further optimization. Accordingly, thirteen samples were prepared, and treatment was carried out by varying the concentration of sodium perborate (main factor), using a single factor completely randomized design. In addition, possible chemical combinations and process sequences were tested in search for improved whiteness.

\section{Whiteness Index (WI)}

The results in Figure 1 showed that increasing the SPB concentration improved the whiteness. This may be due to the liberation of more perhydroxyl ions, which are mainly responsible for bleaching at higher concentration of SPB [19].

Commercially, sodium perborate tetrahydate, $\mathrm{NaBO}_{3} \cdot 4 \mathrm{H}_{2} \mathrm{O}$, is prepared by reaction of sodium borate with hydrogen peroxide $\left(\mathrm{H}_{2} \mathrm{O}_{2}\right)$, and it is considered to be a solid form of hydrogen peroxide. When dissolved in water, sodium perborate releases back hydrogen peroxide (Equation 3).

$\mathrm{NaBO}_{3} \cdot 4 \mathrm{H}_{2} \mathrm{O} \rightleftharpoons \mathrm{H}_{2} \mathrm{O}_{2}+\mathrm{Na}+\mathrm{BO}_{2}+3 \mathrm{H}_{2} \mathrm{O}$

Therefore, the component in sodium perborate responsible for bleaching is hydrogen peroxide [14].

Magdy Zahran [14] summarized several theories regarding the mechanism of hydrogen bleaching. According to early theories; nascent oxygen was considered to be reactive species in hydrogen peroxide bleaching. This nascent (atomic) oxygen was claimed to separate easily from perhydroxyl anion $\left(\mathrm{HO}_{2}^{-}\right)$in accordance to (Equation 4).

$$
\mathrm{HO}_{2} \rightleftharpoons \mathrm{HO}^{*}+[\mathrm{O}]
$$

In the modern view the bleaching effect is attributed to the perhydroxyl anion $\left(\mathrm{HO}_{2}^{-}\right)$. According this view, hydrogen peroxide is present in aqueous solution in dissociation equilibrium with perhydroxyl anion $\left(\mathrm{HO}_{2}^{-}\right)$and peroxo dianion $\left(\mathrm{O}_{2}^{2-}\right)$ (Equation5,6).

$$
\begin{aligned}
& \mathrm{H}_{2} \mathrm{O}_{2} \rightleftharpoons \mathrm{HO}_{2}+\mathrm{H}^{+}- \\
& \mathrm{HO}_{2} \rightleftharpoons \mathrm{O}_{2}{ }^{2-}+\mathrm{H}^{+}-
\end{aligned}
$$

The perhydroxyl anion may further generate other active species according to the following equation.

$\mathrm{HO}_{2}^{-}+\mathrm{H}_{2} \mathrm{O}_{2} \rightarrow \mathrm{HO}_{2}^{*}+\mathrm{HO}^{-}+\mathrm{HO}^{*}$

The perhydroxyl radical $\left(\mathrm{HO}^{*}\right)$ may also dissociate to form radical anion $\left(\mathrm{O}_{2}^{-*}\right)$ known as superoxide which recently considered as active bleach agent [20].

The presence of sodium hydroxide in the solution acts as bleaching activator which enhances the formation of perhydroxyl ions $\left(\mathrm{HO}_{2}\right.$ ), and thereby increasing the extent of oxidative decoloration of the natural colorants in the raw cotton [21].

$$
\mathrm{H}_{2} \mathrm{O}_{2}+\mathrm{OH}^{-} \rightarrow \mathrm{H}_{2} \mathrm{O}+\mathrm{HO}_{2}^{-}
$$

The results in Figure 1 show that the WI gradually increases and attains a maximum value (71.5) at $45 \mathrm{~g} / \mathrm{L}$ SPB concentration and beyond this concentration the increase in WI was marginal. The WI value of $>70$ is considered to be commercially acceptable [22]. This value was also comparable to the commercially bleached cotton used as a standard.

\section{Starch removal and weight loss}

The efficiency of starch removal was evaluated qualitatively using 


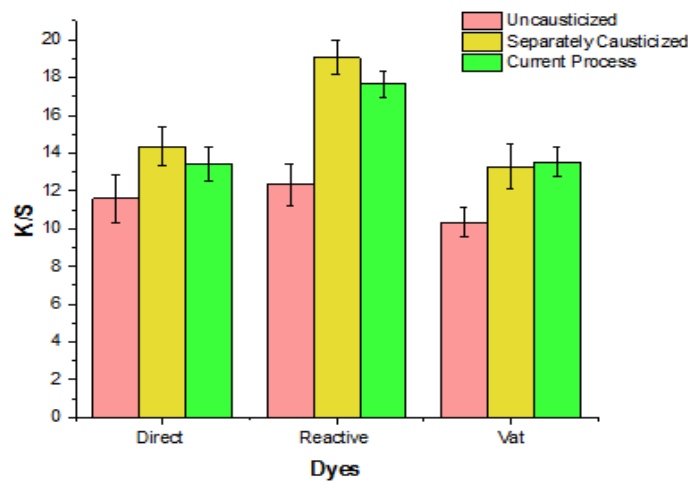

Figure 2: Comparative dye uptake.

the iodine test, and quantitatively by calculating percentage loss in fabric weight. The result from both the tests indicated that the starch removal was effective, which confirms the oxidative role of SPB on the starch sized materials. The absence of deep blue colour during the iodine test showed the removal of starch. It is evident (Table 4) that the percent loss in fabric weight increased with SPB concentration upto $30 \mathrm{~g} / \mathrm{L}$. Increasing the SPB concentration enhances the oxidative degradation of the starch, and non-starch polysaccharides adhered on the fiber surfaces [14]. Above $30 \mathrm{~g} / \mathrm{L}$ SPB concentration, the increment in weight loss was marginal, indicating the complete removal of the starch and other impurities.

\section{Water absorbency}

As seen from the results in Table 4, all the samples showed excellent wettability regardless of the concentration of SPB. Conventionally, cotton fabric scouring is performed by alkali treatment, and effective removal of impurities is achieved by boiling in $3-6 \% \mathrm{NaOH}$ to saponify oils, fats and waxes present in cotton [23]. In present case, the $\mathrm{NaOH}(140 \mathrm{~g} / \mathrm{L})$ was quite high for effective scouring for good wettability.

\section{Strength loss}

The major drawback of treating cotton with oxidizing agents is the loss in tensile strength. Therefore, preserving the fabric mechanical properties is a key aspect to be considered during fabric pre-treatment. In this regard, tensile strength is one of the most important indicators of the degradation of the fabric during pre-treatment. An increase in SPB concentration resulted in a decrease in warp yarn strength. This phenomenon was expected and agrees with the study reported by Vigo [24] especially in the presence of higher amount of $\mathrm{NaOH}$. The loss of tensile strength at higher SPB and $\mathrm{NaOH}$ concentrations may be related to the removal of the non-cellulosic component from the fabric as well as some oxidative degradation of the cellulose chains [19]. However, the results showed that a higher WI can be achieved with a tolerable percent of strength loss.

\section{Effectiveness of causticization}

Causticization of cotton is carried out when the sole purpose is to improve dye uptake. In order to confirm the effectiveness of causticization in a single step process, the three samples (commercially bleached uncausticized, commercially bleached and causticized and the current process of single step desizing, scouring, bleaching and causticizing) were dyed using selected direct reactive and vat dyes under identical conditions for respective dye class. As seen from Figure 2, the new combined process was found to have a higher dye uptake compared to commercially bleached cotton and only marginally less dye uptake compared to commercially bleached and separately causticized cotton in case of direct and reactive dyes and comparable with vat dye.

The effect of causticization in increase in dye uptake is attributed to the swelling effect of caustic soda of high concentration and breaking of H-bonds at the surface of intra-crystalline regions of cellulose. On removal of caustic soda on washing the reformation of $\mathrm{H}$-bonds is not to the same extent as uncausticized cotton. This phenomenon gives increase of free $\mathrm{OH}$ groups in cotton which are responsible for increase in dye uptake [25]. The results were indicative of the fact that the new process suggested in this research is effective in achieving a single stage desizing, scouring, bleaching and causticizing of cotton fabric having additional benefit of increase in dye uptake.

\section{Conclusion}

This study shows that it is possible to make a grey cotton fabric ready for dyeing and finishing in one-step, at economical cost in a short time. With the one-step process reported in this study, it is possible to attain instantaneous water absorbency, minimum loss of tensile strength $(8.6 \%$ average at $45 \mathrm{~g} / \mathrm{L})$ and whiteness index greater than 71 on the CIE whiteness scale.

The increase in the dye uptake of direct, reactive and vat dye classes compared to commercially bleached cotton confirms that the effectiveness of causticization process along with desizing, scouring and bleaching.

The optimum recipe consists of padding the gray cotton fabric using a two-dip, two-nip technique in a bath containing $\mathrm{NaOH}$ $140 \mathrm{~g} / \mathrm{L} ; \mathrm{SPB} 45 \mathrm{~g} / \mathrm{L}$; wetting agent $1 \mathrm{~g} / \mathrm{L}$, batching for $30 \mathrm{~min}$ at room temperature and washing the treated fabric with $1 \mathrm{~g} / \mathrm{L}$ emulsifier twice for 15 minutes each at boil with $3 \%$ (owf) SPB added during the second wash, rinsed in hot and cold water and air dried.

As compared with the traditional process, the current combined process offers significant saving in process time, chemicals, water and energy with economic advantage and productivity.

Additional research is essential in experimentation on a pilot plant and industrial scale to ascertain the feasibility of the process on commercial scale.

\section{Acknowledgement}

The authors are thankful to the Ethiopian Institute of Textile and Fashion Technology, Bahir Dar University, Ethiopia and for Erasmus Mundus Joint Doctorate Program; Sustainable Management and Design for Textile (SMDTex).

\section{References}

1. Clark M. Pre-treatment and preparation of textile materials prior to dyeing, Handbook of Textile and Industrial Dyeing. Woodhead Publishing-Elsevier. 2011.

2. Brushwood DE. Noncellulosic constituents on raw cotton and their relationship to fiber physical properties. Text Res J. 2003; 73: 912-916.

3. Karmakar SR. Chemical technology in the pre-treatment processes of textiles. Elsevier. 1999. 
4. Wagaw T, Chavan RB. Optimization of Caustic Soda Concentration for Causticization of Cotton. OMICS Open Access Scientific Reports. 2012; 1 $1-6$.

5. Parikh MR. Combined pretreatment of cotton. Colourage. 1971; 18: 42.

6. Sahkari VD. Special chemicals for single stage bleaching of natural and synthetic textiles. Invention intelligence. 1983; 18: 249

7. Gulrajani ML, Sukumar N. Solvent assisted preparatory process for cotton. J Soc Dyers Colour. 1984; 100: 21

8. Prabhaharan M, Venkat Rao J. Combined desizing, scouring and bleaching of cotton using ozone. Indian J Fibre Tex Res. 2003; 28: 437-443.

9. Tzanov T, Calafell M, Guebitz GM. Bio-preparation of cotton fabrics, Enzyme and Microbial. Technology. 2001; 29: 357-362.

10. Spicka N, Forte-Tavcer P. Complete enzymatic pre-treatment of cotton fabric with incorporated bleach activator. Text Res J. 2012; 83: 566-573.

11. Teli MD, Adere TT. Short and Efficient Desizing and Scouring Process of Cotton Textile Materials. Int J of Eng Trends and Technol. 2016; 35: 256-269.

12. Harane RS, Tayade PB, Mehra NR, Adivarekar RV. A facile energy and water-conserving process for cotton dyeing. Int J Energy Environ Eng. 2014 5: 96.

13. Huang KS, Jan EP, Lu LA. A new process for the desizing, scouring and bleaching of cotton/nylon fabrics with tetraacetylethylenediamine, Cellulose Chem Technol. 2007; 41: 43-50.

14. Zahran MK. One-step process for desizing, scouring and bleaching of cotton fabric using a novel eco-friendly bleaching agent. J of Textile Association. 2006; 153-158
15. Wagaw T, Chavan RB. Causticization followed by combined desizing scouring and bleaching of cotton. Colourage. 2013; 43-47.

16. AATCC Technical Manual, Water absorbency test (AATCC 79:2007). USA: American Association of Textile Chemists and Colorists. 2008; 99-100.

17. AATCC Technical Manual, Whiteness of Textiles AATCC Test Method 110 2005. USA: American Association of Textile Chemists and Colorists. 2008; 163-164

18. Nicoll WD, Smith AF. Stability of dilute alkaline solutions of hydrogen peroxide. Industrial and Engineering Chemistry. 1955; 47: 2548-2554.

19. Prabaharan M, Almeida L, Process optimization in tetraacetyl ethylenediamine activated sodium perborate bleaching of cotton. Indian J Fibre Text Res. 2004; 29:343-349.

20. Dannacber J, Schlenker W. The Mechanism of Hydrogen Peroxide Bleaching Textile Chemist \& Colorist. 1996; 28: 24-28.

21. Zeronian SH, Inglesby MK. Bleaching of cellulose by hydrogen peroxide. Cellulose. 1995; 2: 265-272.

22. El Shafie AE, Fouda MMG, Hashem M. One-step process for bio-scouring and peracetic acid bleaching of cotton fabric. Carbohydrate polymers. 2009; 78: 302-308.

23. Lewin M. Handbook of Fiber Science and Technology Volume 2, Chemical Processing of Fibers and Fabrics--Functional Finishes. CRC Press. 1984.

24. Vigo TL. Textile processing and properties: Preparation, dyeing, finishing and performance. Elsevier; 1994.

25. Inglesby MK, Zeronian SH. The accessibility of cellulose as determined by dye absorption. Cellulose. 1996; 3: 165-181.
Adv Res Text Eng - Volume 2 Issue 1 - 2017

ISSN: 2572-9373 | www.austinpublishinggroup.com

Molla et al. (C) All rights are reserved
Citation: Molla TA, Chavan RB and Nierstrasz V. Combined Pre-Treatment and Causticization of Cotton Fabric for Improved Dye Uptake. Adv Res Text Eng. 2017; 2(1): 1016. 